\title{
RELAP-7 Level 2 Milestone Report: Demonstration of a Steady State Single Phase PWR Simulation with RELAP-7
}

David Anders

Ray Berry

Derek Gaston

Richard Martineau

John Peterson

Hongbin Zhang

Haihua Zhao

Ling Zou

May 2012

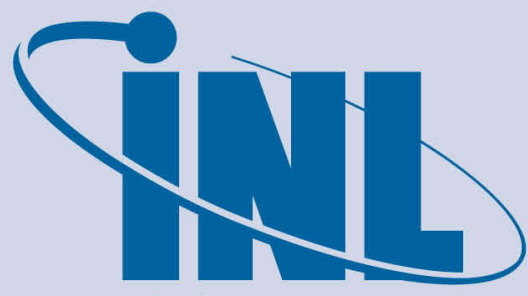

Idaho National Laboratory

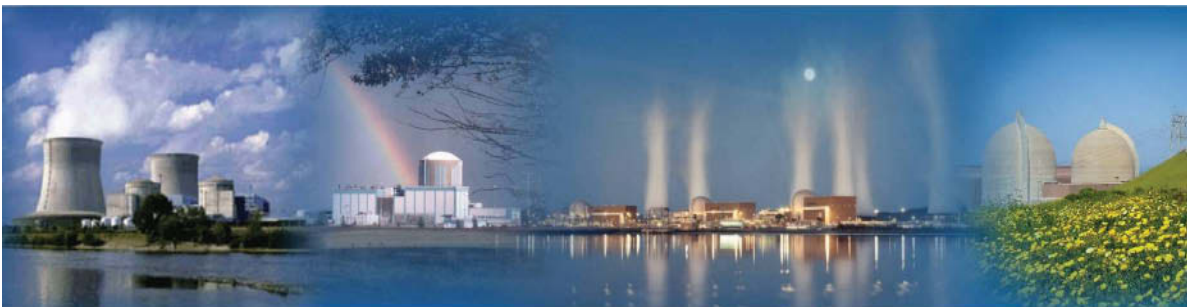

The INL is a U.S. Department of Energy National Laboratory operated by Battelle Energy Alliance 
INL/EXT-12-25924

\title{
RELAP-7 Level 2 Milestone Report: Demonstration of a Steady State Single Phase PWR Simulation with RELAP-7
}

\author{
David Anders \\ Ray Berry \\ Derek Gaston \\ Richard Martineau \\ John Peterson \\ Hongbin Zhang \\ Haihua Zhao \\ Ling Zou
}

May 2012

\author{
Idaho National Laboratory \\ Idaho Falls, Idaho 83415 \\ http://www.inl.gov
}

\author{
Prepared for the \\ U.S. Department of Energy \\ Office of Nuclear Energy \\ Under DOE Idaho Operations Office \\ Contract DE-AC07-05ID14517
}




\section{DISCLAIMER}

This information was prepared as an account of work sponsored by an agency of the U.S. Government. Neither the U.S. Government nor any agency thereof, nor any of their employees, makes any warranty, expressed or implied, or assumes any legal liability or responsibility for the accuracy, completeness, or usefulness, of any information, apparatus, product, or process disclosed, or represents that its use would not infringe privately owned rights. References herein to any specific commercial product, process, or service by trade name, trade mark, manufacturer, or otherwise, do not necessarily constitute or imply its endorsement, recommendation, or favoring by the U.S. Government or any agency thereof. The views and opinions of authors expressed herein do not necessarily state or reflect those of the U.S. Government or any agency thereof. 


\section{EXECUTIVE SUMMARY}

The RELAP-7 code is the next generation nuclear reactor system safety analysis code being developed at Idaho National Laboratory (INL). The code is based on INL's modern scientific software development framework - MOOSE (Multi-Physics Object-Oriented Simulation Environment). This report summarizes the initial results of simulating a model steady-state single phase PWR problem using the current version of the RELAP-7 code. The major purpose of this demonstration simulation is to show that RELAP-7 code can be rapidly developed to simulate single-phase reactor problems.

RELAP-7 is a new project started on October $1^{\text {st }}, 2011$. It will become the main reactor systems simulation toolkit for RISMC (Risk Informed Safety Margin Characterization) and the next generation tool in the RELAP reactor safety/systems analysis application series (the replacement for RELAP5). The key to the success of RELAP-7 is the simultaneous advancement of physical models, numerical methods, and software design while maintaining a solid user perspective. Physical models include both PDEs (Partial Differential Equations) and ODEs (Ordinary Differential Equations) and experimental based closure models. RELAP-7 will eventually utilize well posed governing equations for multiphase flow, which can be strictly verified. Closure models used in RELAP5 and newly developed models will be reviewed and selected to reflect the progress made during the past three decades. RELAP-7 uses modern numerical methods, which allow implicit time integration, higher order schemes in both time and space, and strongly coupled multi-physics simulations. RELAP-7 is written with object oriented programming language $\mathrm{C}++$. Its development follows modern software design paradigms. The code is easy to read, develop, maintain, and couple with other codes. Most importantly, the modern software design allows the RELAP-7 code to evolve with time.

RELAP-7 is a MOOSE-based application. MOOSE (Multiphysics Object-Oriented Simulation Environment) is a framework for solving computational engineering problems in a well-planned, managed, and coordinated way. By leveraging millions of lines of open source software packages, such as PETSC (a nonlinear solver developed at Argonne National Laboratory) and LibMesh (a Finite Element Analysis package developed at University of Texas), MOOSE significantly reduces the expense and time required to develop new applications. Numerical integration methods and mesh management for parallel computation are provided by MOOSE. Therefore RELAP-7 code developers only need to focus on physics and user experiences. By using the MOOSE development environment, RELAP-7 code is developed by following the same modern software design paradigms used for other MOOSE development efforts. There are currently over 20 different MOOSE based applications ranging from 3-D transient neutron transport, detailed 3-D transient fuel performance analysis, to long-term material aging. Multi-physics and multiple dimensional analyses capabilities can be obtained by coupling RELAP-7 and other MOOSE based applications and by leveraging with capabilities developed by other DOE programs. This allows restricting the focus of RELAP-7 to systems analysis-type simulations and gives priority to retain and significantly extend RELAP5's capabilities.

During the first half year, MOOSE has been extended to better support system analysis code development. The preliminary RELAP-7 software structure has been designed. Numerical stability schemes for single-phase flow, which are needed for continuous finite element analysis, have been developed. Major physical components have been completed (designed and tested) to 
support the demonstration calculation. There are mainly three types of components:(1) 1-D components, including pipe, core channel, and heat exchanger; (2) 0-D components for setting boundary conditions including time dependent volume, time dependent junction, and time dependent mass flow rate; and (3) 0-D components for connecting 1-D components including junction/branch and pumps. Preliminary input interfaces have been designed.

The case selected for initial demonstration of RELAP-7 is the simulation of a two-loop, steady state PWR system. Although this simulation uses a simplified system model, it is consistent with the detailed level of current system safety analyses. It contains two parallel loops and multiple reactor core flow channels. The simulation begins as a transient problem and progresses toward a converged steady state. The simulation results match the benchmark data very closely. For example, both of the reactor inlet and outlet temperatures match the data in the order of $0.1 \mathrm{~K}$.

In summary, the MOOSE based RELAP-7 code development is a new effort. The MOOSE framework enables rapid development of the RELAP-7 code. With only a few of months of development efforts, a model single-phase PWR problem has been successfully simulated to steady state, which demonstrates the initial capabilities of the RELAP-7 code. The developmental efforts and results are very encouraging and demonstrate the RELAP-7 project is on a path to success. The next stage of development is to demonstrate two-phase modeling capability through a simplified BWR station black out analysis, which will be reported in the next demonstration simulation report. 


\section{ACKNOWLEDGMENTS}

Development of a safety analysis code is the result of team effort and requires the diverse talents of experts. The following lists the members of current RELAP-7 development team:

- Project Manager: Richard Martineau

- Reactor Simulation Team: Haihua Zhao (PI), Ling Zou, Hongbin Zhang

- Software Design Team: Derek Gaston (lead), David Andrs, John Peterson

- Theory Team: Ray Berry (lead), Richard Martineau, Samet Kadioglu, Brandon M. Blackburn

The acknowledgement is also made of the MOOSE team. Their close collaboration and support is essential to the success of this project. 


\section{CONTENTS}

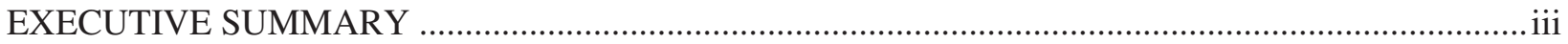

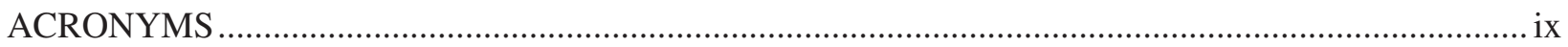

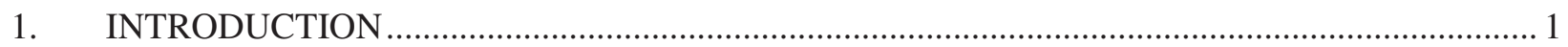

2. CURRENT STATUS OF THE RELAP-7 CODE ...................................................................... 3

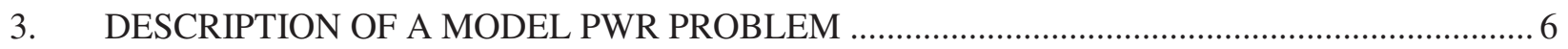

3.1 Core and Fuel Assembly Geometry .......................................................................... 7

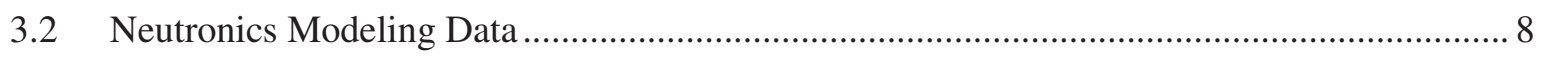

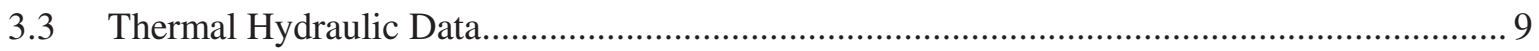

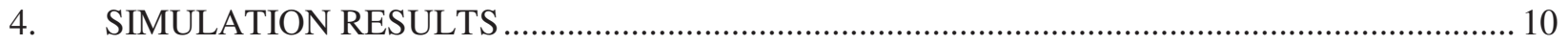

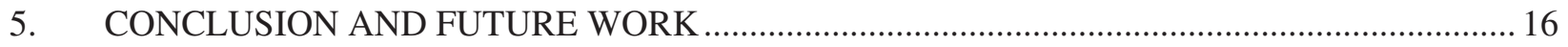

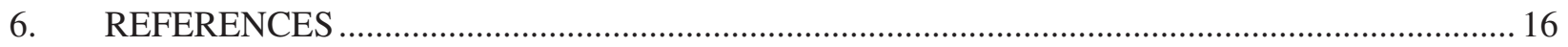




\section{FIGURES}

Figure 1. The schematic of the CoreChannel component. ......................................................................... 4

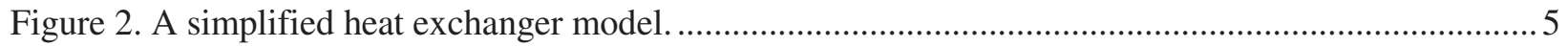

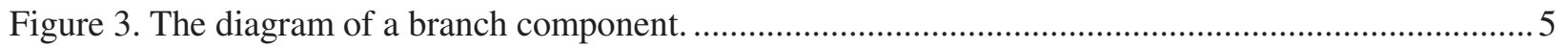

Figure 4. Schematics of the model PWR problem................................................................................ 7

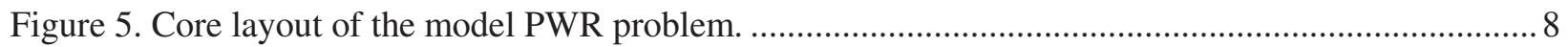

Figure 6. End of cycle hot full power assembly relative radial power distribution (quarter core

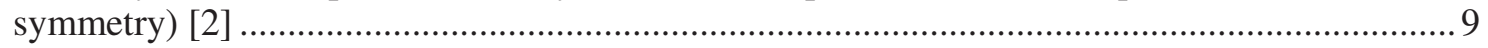

Figure 7. RELAP-7 calculated fluid temperature field .......................................................................... 11

Figure 8. RELAP-7 calculated fluid temperature in three core channels................................................ 11

Figure 9. Axial temperature profiles along the fuel length ................................................................... 12

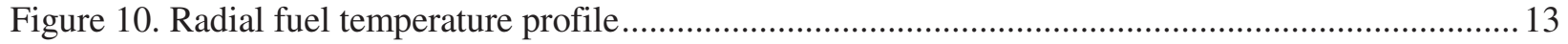

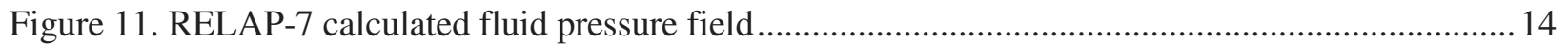

Figure 12. RELAP-7 calculated fluid velocity field ........................................................................... 14

Figure 13. Fluid temperature in the loop-A heat exchanger ............................................................... 15

Figure 14. Fluid temperature in the loop-A heat exchanger along the heat exchanger height................... 16 


\section{TABLES}

Table 1. Key Features Comparison between RELAP5 and RELAP-7 ……............................................ 2

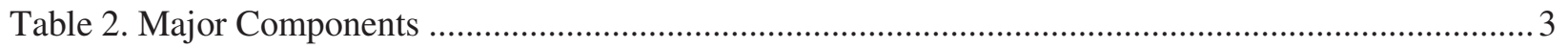

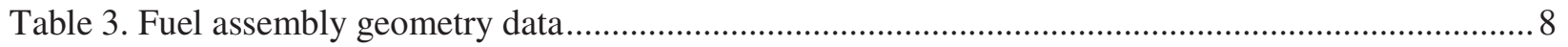

Table 4. Power distribution fraction and power density of the model PWR problem ................................9

Table 5. Major thermal hydraulic parameters of the model PWR problem.............................................. 10 


\section{ACRONYMS}

0-D Zero Dimensional

1-D One Dimensional

3-D Three Dimensional

DOE Depart of Energy

HX Heat Exchanger

INL Idaho National Laboratory

MOOSE Multi-Physics Object-Oriented Simulation Environment

MSLB Main Steam Line Break

NPP Nuclear Power Plant

ODE Ordinary Differential Equation

OECD Organization of Economic Cooperation and Development

PDE Partial Differential Equation

PWR Pressurized Water Reactor

RELAP5 Reactor Excursion and Leak Analysis Program 5

RELAP-7 Reactor Excursion and Leak Analysis Program 7

RISMC Risk Informed Safety Margin Characterization

TMI-1 Three Mile Island Unit 1 


\section{INTRODUCTION}

The RELAP-7 code is the next generation nuclear reactor system safety analysis code being developed at the Idaho National Laboratory (INL). INL has a legacy of developing reactor system safety analysis codes spanning several decades with its flagship products - the RELAP3, RELAP4, and RELAP5 codes - widely used world wide to perform reactor safety analyses. The RELAP5 code was originally developed in the 1970s with incremental improvements made over the years. However, the code has not evolved much from the perspectives of numerical techniques, software engineering and fundamental physical models. The code treats individual physics separately and coupling is done explicitly which imposes stability restrictions on the time step size. This loosely coupled approach limits the accuracy of the code, at best, to first order in time and space. The two-phase flow models in RELAP5 are ill-posed (in the sense of Hadamard). This means that the partial differential equations that describe the physics do not have unique solutions or that they do not depend continuously on the initial data. The code relies on inherent artificial numerical diffusion from its first order accurate spatial discretization to regularize the solution. Because this regularizing artifical diffusion diminishes with mesh size, a grid converged solution is unattainable. This also prevents modern $2^{\text {nd }}$ - or higher-order spatial discretization methods from being used because they do not have enough "induced error" to keep the solution regularized. Additionally, the RELAP5 code is written in FORTRAN with no parallelization capability. This makes it difficult to maintain and expand the code. Without parallelization capability, the code cannot take full advantage of the modern day computer architecture. Over the past three decades, computer speed and memory have grown exponentially to make high fidelity simulations of reactor systems possible. Also, significant progress has been made in the development of innovative, fully coupled algorithms for solving the partial differential equations describing strongly coupled and complex phenomena like those in a nuclear power plant. These new algorithms provide a mechanism to remove traditional operator splitting errors, and to allow the coupled equations to be solved implicitly with improved accuracy and efficiency. Modern well-posed two-phase flow models will allow the employment of more accurate temporal andspatial discretization.

RELAP-7 is a new project started on October $1^{\text {st }}, 2011$. It will become the main reactor systems simulation toolkit for RISMC (Risk Informed Safety Margin Characterization) and the next generation tool in the RELAP reactor safety/systems analysis application series (the replacement for RELAP5). The RELAP-7 code aims at taking advantage of the progresses made in the past several decades to achieve simultaneous advancement of physical models, numerical methods and software design. Table 1 provides a summary of comparisons of the key features between RELAP5 and RELAP-7. Physical models include both PDEs (Partial Differential Equations) or ODEs (Ordinary Differential Equations) and closure models based on experiments. RELAP-7 will use well-posed PDEs governing multiphase flows which can be strictly verified. Closure models used in RELAP5 and newly developed models will be reviewed and selected to reflect the progress made during the past three decades. RELAP-7 uses modern numerical methods allowing implicit time integration, higher order schemes in both time and space, and strongly coupled multi-physics simulations. RELAP-7 is written with object oriented programming language $\mathrm{C}++$. Its development follows modern software design paradigms. The code will be easy to read, develop, maintain, couple with other codes. All these bode well for the RELAP-7 code to evolve over time. 
Table 1. Key Features Comparison between RELAP5 and RELAP-7

\begin{tabular}{|c|c|c|}
\hline & RELAP5 & RELAP-7 \\
\hline Capacities & $\begin{array}{l}\text { Short transients } \\
\text { with strong } \\
\text { energy and } \\
\text { momentum } \\
\text { sources }\end{array}$ & $\begin{array}{l}\text { Plus: long transients, weak driving sources; } \\
\text { multiple dimensional capabilities and additional } \\
\text { physics available by coupling with several } \\
\text { MOOSE based applications }\end{array}$ \\
\hline \multirow[t]{2}{*}{ Software design } & Fortran $77,90 / 95$ & $\mathrm{C}++$ \\
\hline & $\begin{array}{l}\text { Modular } \\
\text { programming }\end{array}$ & Modern software design, MOOSE \\
\hline $\begin{array}{l}\text { Numerical } \\
\text { methods }\end{array}$ & $\begin{array}{l}\text { Semi-implicit } 1^{\text {st }} \\
\text { order accuracy in } \\
\text { time and space in } \\
\text { theory }\end{array}$ & $\begin{array}{l}\text { Jacobian-free Newton-Krylov nonlinear solver } \\
(\mathrm{JFNK}) ; 2^{\text {nd }} \text { order in both time and space; fully } \\
\text { coupled multiphysics; better operator split } \\
\text { method PCICE as preconditioner }\end{array}$ \\
\hline Two phase flow & $\begin{array}{l}\text { ill-posed, 6- } \\
\text { equations }\end{array}$ & well-posed, 7-equations \\
\hline $\mathrm{V} \& \mathrm{~V}$ & only validation & $\begin{array}{l}\text { both verification and validation; RELAP5 } \\
\text { validation data plus new available data }\end{array}$ \\
\hline
\end{tabular}

RELAP-7 is a MOOSE based application. MOOSE is INL's framework for solving computational engineering problems in a well-planned, managed, and coordinated way. By leveraging millions of lines of open source software packages such as PETSC (a nonlinear solver developed at Argonne National Laboratory) and LibMesh (a Finite Element Analysis package developed at University of Texas), MOOSE significantly reduces the expense and time required to develop new applications. Numerical methods, mesh management, and parallel computational controls are all provided within MOOSE. Therefore RELAP-7 code developers only need to focus on physics and user experiences. This has greatly enhanced the productivity and promoted rapid code development. Therefore, the RELAP-7 code is being developed by following the same modern software design paradigms used for MOOSE development. There are currently over 20 different MOOSE based applications ranging from 3-D transient neutron transport, detailed 3-D transient fuel performance analysis, to long-term material aging. Multi-physics and multiple dimensional analyses capabilities can be obtained by coupling RELAP-7 and other MOOSE based applications and by leveraging capabilities developed by other DOE programs. This allows restricting the focus of RELAP-7 to systems analysis-type simulations and gives priority to retain and significantly extend RELAP5's capabilities. 


\section{CURRENT STATUS OF THE RELAP-7 CODE}

During the past half a year (2012), MOOSE has been extended to better support system analysis code development. Preliminary RELAP-7 software structure has been designed. Numerical stability schemes for single-phase flow, which are needed for continuous finite element analysis, have been developed. Preliminary version of major physical components to support the demonstration calculation have been designed, tested, and finished.

A real reactor system is very complex and may contain hundreds of different physical components. Therefore, it is impractical to preserve real geometry for the whole system. Instead, simplified thermal hydraulic models are used to represent the major physical components and describe major physical processes. A set of basic components to build a reactor system has been implemented in the RELAP-7 code and they are listed in Table 2. There are mainly three types of components: (1) 1-D components including pipe, core channel, and heat exchanger; (2) 0-D components for setting boundary conditions including time dependent volume, time dependent junction, and time dependent mass flow rate; and (3) 0-D components for connecting 1-D components including junction/branch and pumps. Preliminary input interfaces have been designed.

Table 2. Major Components

\begin{tabular}{lll}
\hline Component name & Descriptions & Dimension \\
\hline Pipe & $\begin{array}{l}\text { Fluid flow within 1-D solid structure with } \\
\text { wall friction and heat transfer }\end{array}$ & 1-D \\
\hline \multirow{2}{*}{ CoreChannel } & $\begin{array}{l}\text { Simulating reactor flow channel and fuel } \\
\text { rod, including 1-D flow and perpendicular } \\
\text { 1-D fuel rod heat conduction }\end{array}$ & 1-D \\
\hline HX & $\begin{array}{l}\text { Heat exchanger model, including fluid flow } \\
\text { in two sides and heat conduction through } \\
\text { the solid wall }\end{array}$ & 1-D \\
\hline \multirow{2}{*}{ TimeDependentVolume } & $\begin{array}{l}\text { Time dependent volume, which provides } \\
\text { pressure and temperature boundaries for 1- } \\
\text { D components }\end{array}$ & 0-D \\
\hline TimeDependentJunction & $\begin{array}{l}\text { Time dependent junction, which provides } \\
\text { velocity and temperature boundaries for 1-D } \\
\text { components }\end{array}$ & 0-D \\
\hline Tdm & $\begin{array}{l}\text { Time dependent mass flow, which provides } \\
\text { mass flow boundary for 1-D components }\end{array}$ & 0-D \\
\hline Branch & $\begin{array}{l}\text { Multiple in and out 0-D junction, which } \\
\text { provides form loss coefficients (K) }\end{array}$ & 0-D \\
\hline Pump & $\begin{array}{l}\text { A junction model with momentum source } \\
\text { connecting two 1-D components }\end{array}$ & 0-D \\
\hline Heat structure & A component to simulate solid structures & 1-D, 2-D, 3-D \\
\hline PointKinetics & Point Kinetics Model, 0-D neutronics model & 0-D \\
\hline
\end{tabular}

All the components except for heat structure and point kinetics are used in the steady state demonstration simulation. Heat structure and point kinetics are only needed for general reactor 
transient simulations. Here we only concern single-phase fluid. To develop a system analysis code, numerical methods, mesh management, equation of states, fluid transport properties, solid material properties, neutronics properties, pressure loss and heat transfer closure laws, and good user input/output interfaces are all indispensible. Those parts will be discussed in other documents. The following briefly discuss the functions of major components.

Pipe is the most basic while most important component in the RELAP-7 code. For nonisothermal case, it solves three equations: continuity, momentum and energy equations (continuity and momentum only, if isothermal). Wall friction factors and convective heat transfer coefficients are calculated through closure laws or provided by user inputs. Gravity effect is taken into account by pipe orientation and flow direction.

CoreChannel is the component designed to simulate coolant flow as well as the conjugated heat transfer between coolant flow and the fuel rod. Figure 1 shows the schematic of the CoreChannel model. The fuel rod is divided into the same number of segments as that of coolant flow pipe elements. Each rod segment is further simulated as 1-D thermal conduction model perpendicular to the fluid flow model. Both plate type of fuel rod and cylindrical fuel rod can be simulated. The solid fuel part is able to deal with typical PWR fuel rod with complex clad/gap/fuel pellet geometries. The flow model and conjugated heat transfer model are strongly coupled instead of loosely coupled in RELAP5.

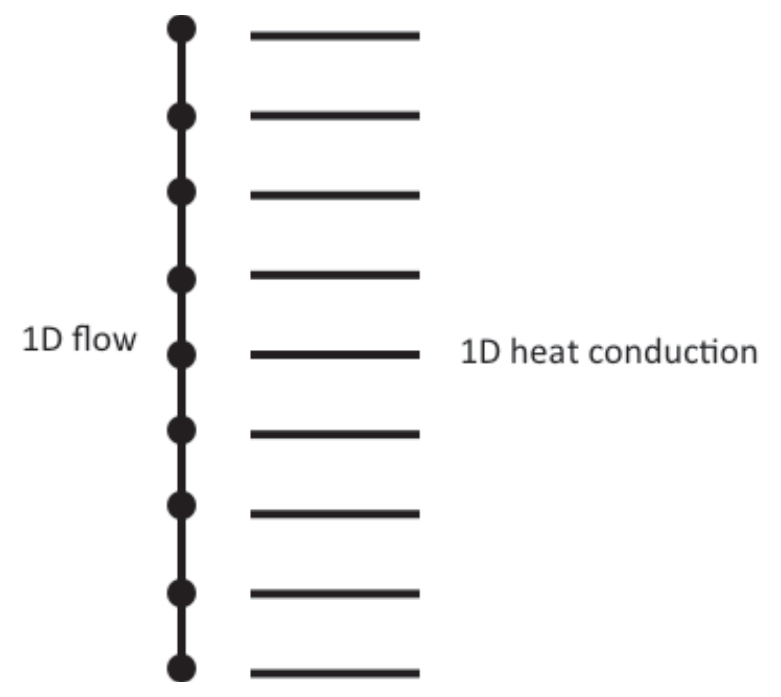

Figure 1. The schematic of the CoreChannel component.

A simple Heat Exchanger (HX) is a combination of two pipes and a solid wall in between, as shown in Figure 2 (more complicated and realistic steam generator will be available in the future). Similar to CoreChannel model, flow model and conjugated heat transfer model are strongly coupled. 


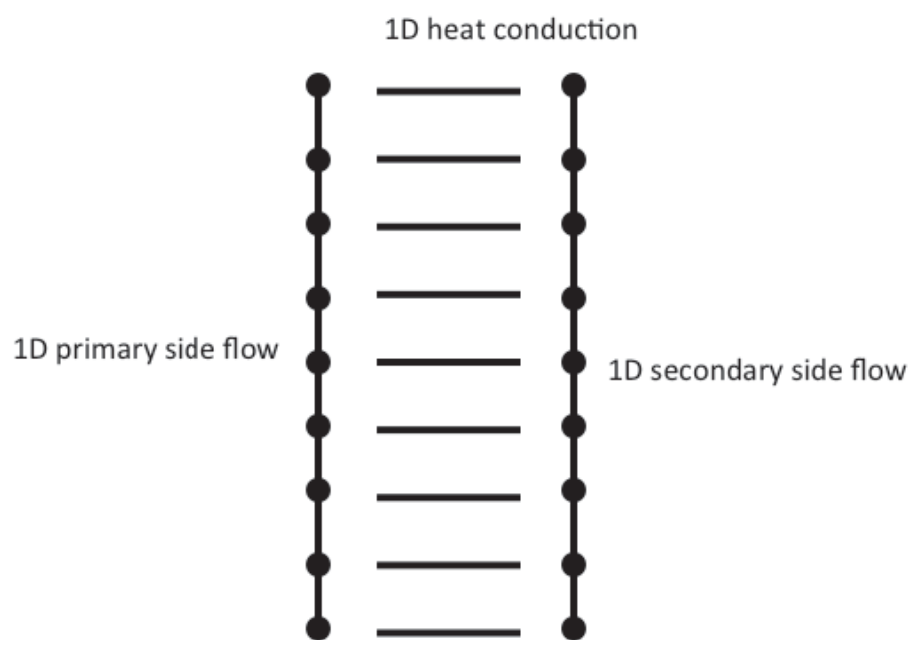

Figure 2. A simplified heat exchanger model.

Time Dependent Volume is a component which provides a time dependent pressure and temperature boundary to its neighboring components. It is a boundary condition type of component without any number of degrees, i.e., it doesn't add any entries to the global unknown vector. In general, it provides a pressure and a temperature boundary condition to its connected pipe. Time Dependent Junction and Time Dependent Mass Flow rate have similar functions with different boundary condition types.

A Branch is basically a junction with multiple inlets and outlets as shown in Figure 3. 3. Branch has single/multiple inlets and single/multiple outlets, of which cross-sectional areas can be different. Each connection has its form loss coefficient K, which in general accouts for pressure loss due to sudden expansion/contraction, mixing, etc.

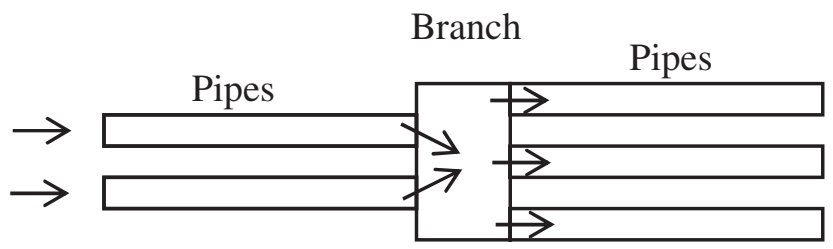

Figure 3. The diagram of a branch component.

A simple Pump can be treated as a single junction conneting two pipes, and provides momentum source into the system. For steady state along positive flow direction, the pump model provides a nominal pump head. For reverse flow, the pump provides large flow resistance. A typical large form loss coefficient $\mathrm{K}$ inputted by users is used under this condtion. More realistic pump models like RELAP5 pump model will be developed later as planned. The RELAP5 pump model is a volume-oriented component, and the head developed by the pump is 
apportioned equally between the suction and discharge junctions that connect the pump volume to the system. The pump head and torque are defined by empirical homologous pump performance model. The pump rotational speed is defined by a pump drive model. The derivative of the pump head with respect to the volumetric flow rate is obtained from the empirical steadystate homologous pump performance model, using the assumption that the pump speed is constant.

\section{DESCRIPTION OF A MODEL PWR PROBLEM}

A model PWR problem has been setup based on the parameters specified in the OECD main steam line break (MSLB) benchmark problem [2]. The reference design for the OECD MSLB benchmark problem is derived from the reactor geometry and operational data of the TMI-1 Nuclear Power Plant (NPP), which is a 2772 MW two loop pressurized water reactor.

Figure 4 shows the schematics of the PWR model problem to be analyzed with RELAP-7. The reactor vessel model consists of the Downcomers, the Lower Plenum, the Reactor Core Model and the Upper Plenum. CoreChannels (flow channels with heat structure attached to each of them) were used to describe the reactor core. Each CoreChannel represents one or thousands of real cooling channels and fuel rods. In this demonstration simulation, the core model consists of three parallel CoreChannels and one bypass flow channel. The hot core channel represents the inner relatively hotter zone of the reactor core. The average core channel represents the mid zone of the core and the cold core channel represents the outer zone of the core, respectively. The Lower Plenum and Upper Plenum are modeled with Branch models. There are two primary loops in this model - Loop A and Loop B. Each loop consists of the Hot Leg, a Heat Exchanger and its secondary side pipes, the Cold Leg and a primary Pump. A Pressurizer is attached to the Loop-A piping system to control the system pressure. A complex Pressurizer model has not been implemented in the current version of RELAP-7 code. A Time Dependent Volume component is used to represent the Pressurizer. Since the RELAP-7 code does not have the twophase flow capability yet, single-phase counter current heat exchanger models are implemented to mimic the function of steam generators to transfer heat from the primary side to the secondary side. 


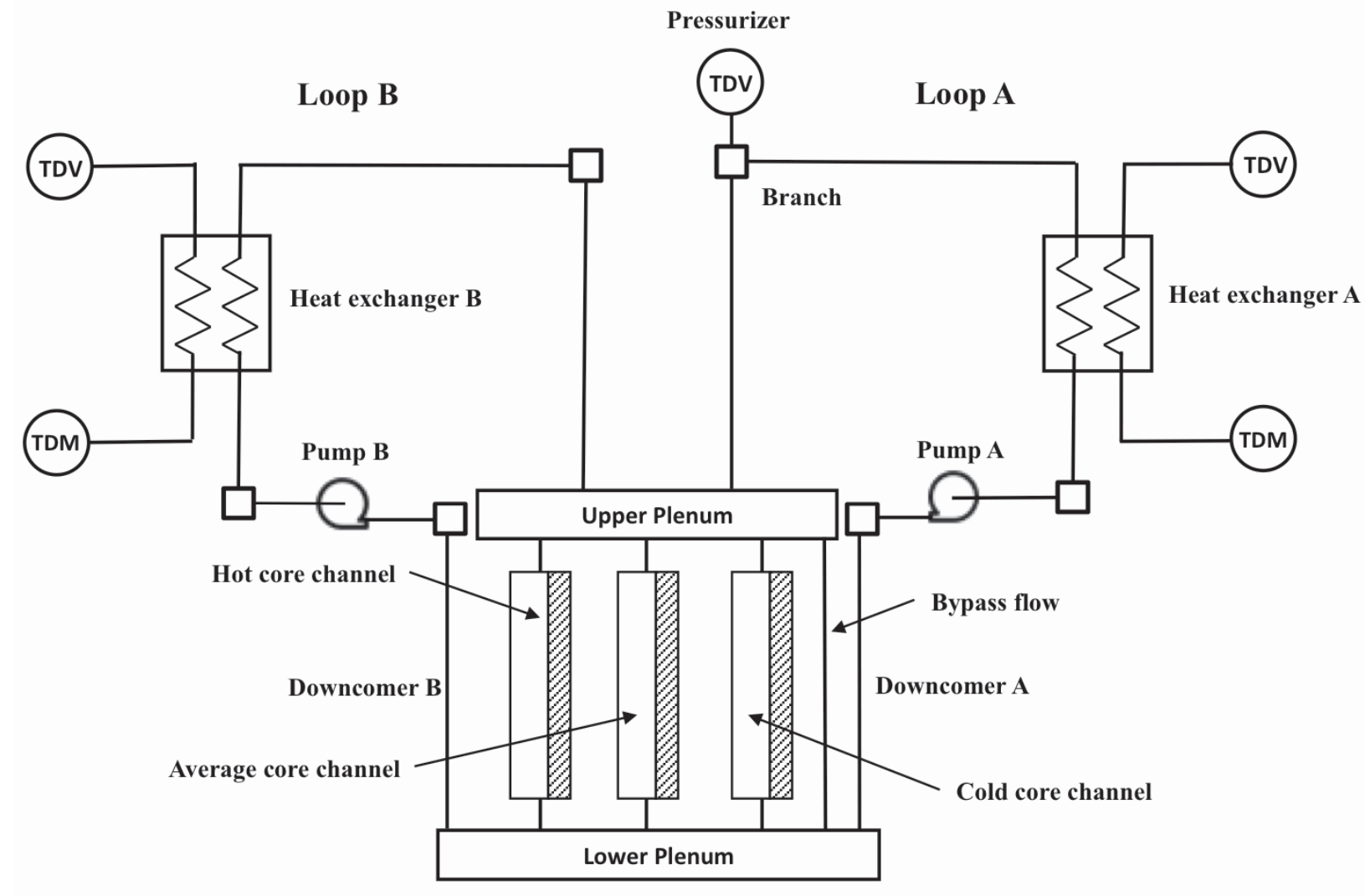

Figure 4. Schematics of the model PWR problem

The following subsections provide more detailed information on the geometry and parameters used for the model problem simulation.

\subsection{Core and Fuel Assembly Geometry}

Figure 5 shows the core layout of the model PWR problem. The reactor consists of 177 fuel assemblies and 64 water reflectors. The core height is assumed to be 12 feet or $3.6576 \mathrm{~m}$. The core is subdivided as zone 1, 2 and 3 as shown in the figure. The 45 assemblies in zone 1 are grouped together as the hot core channel in the RELAP-7 core flow and heat transfer calculations. The 60 assemblies in zone 2 and 72 assemblies in zone 3 are grouped together as the average core channel and the cold core channel respectively. The fuel assembly geometry data is taken from reference [2] and shown in Table 3. . 


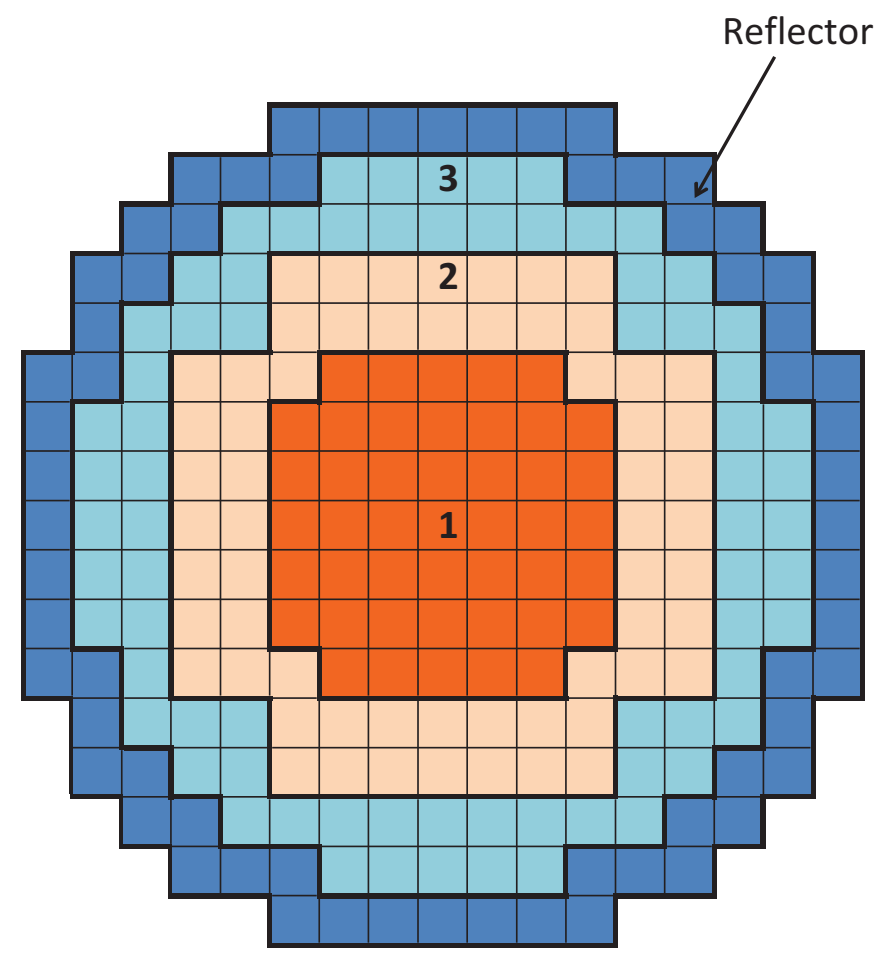

Figure 5. Core layout of the model PWR problem.

Table 3. Fuel assembly geometry data

\begin{tabular}{|l|c|}
\hline \multicolumn{1}{|c|}{ Parameter } & Value \\
\hline Pellet diameter $(\mathrm{cm})$ & 0.9391 \\
\hline Clad diameter $($ outside $)(\mathrm{cm})$ & 1.0928 \\
\hline Clad wall thickness $(\mathrm{cm})$ & 0.0673 \\
\hline Fuel rod pitch $(\mathrm{cm})$ & 1.4427 \\
\hline Guide tube diameter $($ outside $)(\mathrm{cm})$ & 1.3462 \\
\hline Guide tube diameter (inside) $(\mathrm{cm})$ & 1.2650 \\
\hline Geometry & $15 \times 15$ \\
\hline Number of fuel pins & 208 \\
\hline Number of guide tubes & 16 \\
\hline Number of in-core instrument positions per fit & 1 \\
\hline
\end{tabular}

\subsection{Neutronics Modeling Data}

The reactor is assumed to be at end of cycle (EOC), $650 \mathrm{EFPD}(24.58 \mathrm{GWd} / \mathrm{MT}$ average core exposure), with a boron concentration of $5 \mathrm{ppm}$, and equilibrium Xe and $\mathrm{Sm}$ concentration. The 3 -D core neutronics calculation results for the hot full power condition are presented in reference [2]. Figure 6 shows the relative assembly radial power distribution for a quarter of the core. 


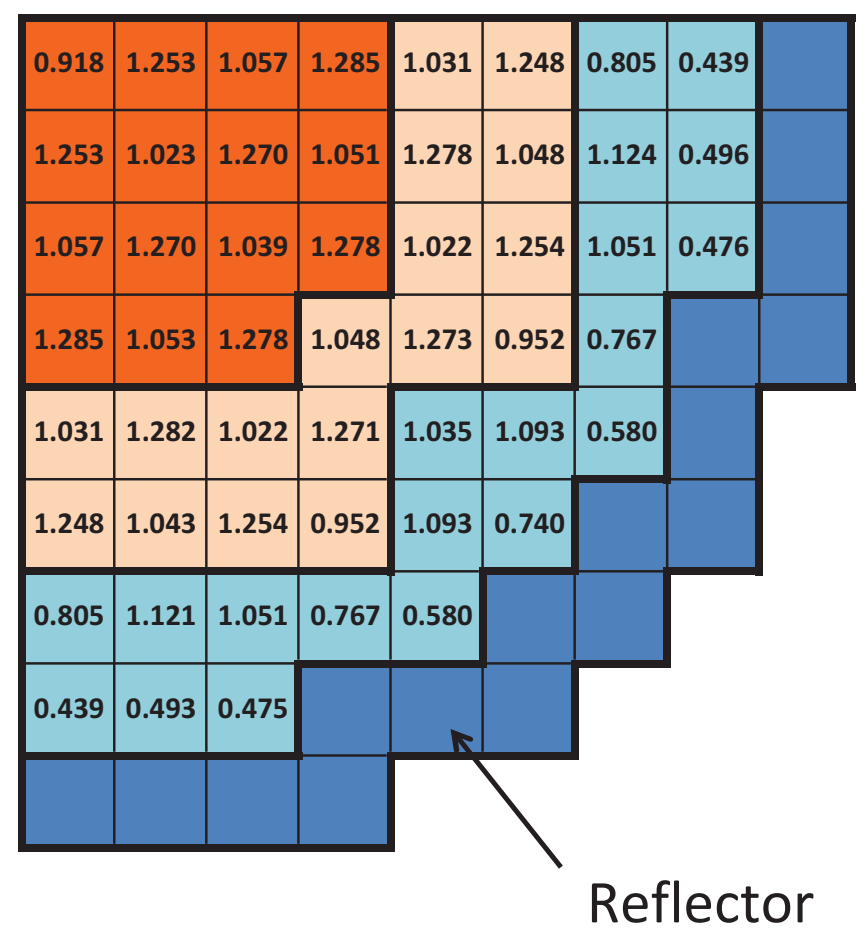

Figure 6. End of cycle hot full power assembly relative radial power distribution (quarter core symmetry) [2]

Using the values presented in Figure 6, the power distribution fraction and power density for each CoreChannel is calculated and shown in Table 4. The power density is inputted into the RELAP-7 model to calculate the heat source.

Table 4. Power distribution fraction and power density of the model PWR problem

\begin{tabular}{|l|c|c|}
\hline Core Channel & Power distribution fraction & $\begin{array}{c}\text { Average fuel pellet } \\
\text { power density }\left(\mathrm{W} / \mathrm{m}^{3}\right)\end{array}$ \\
\hline Hot core channel & 0.3337 & $3.90 \times 10^{8}$ \\
\hline Average core channel & 0.3699 & $3.24 \times 10^{8}$ \\
\hline Cold core channel & 0.2964 & $2.17 \times 10^{8}$ \\
\hline
\end{tabular}

\subsection{Thermal Hydraulic Data}

Some major thermal hydraulic data are shown in Table 5. The RELAP-7 calculated numbers, especially the temperature rise across the core, will be compared with these numbers to ensure that the code is performing correctly. 
Table 5. Major thermal hydraulic parameters of the model PWR problem

\begin{tabular}{|l|c|}
\hline Parameter & Value \\
\hline Core Power $(\mathrm{MWth})$ & 2772 \\
\hline Reactor Coolant System Pressure $(\mathrm{RCS})(\mathrm{MPa})$ & 14.96 \\
\hline Core flow rate $(\mathrm{kg} / \mathrm{sec})$ & 16052.4 \\
\hline Total RCS flow rate $(\mathrm{kg} / \mathrm{sec})$ & 17602.2 \\
\hline Bypass flow rate $(\mathrm{kg} / \mathrm{sec})$ & 1549.8 \\
\hline RCS cold leg temperature $(\mathrm{K})$ & 564.16 \\
\hline RCS hot leg temperature $(\mathrm{K})$ & 591.15 \\
\hline Lower plenum pressure $(\mathrm{MPa})$ & 15.36 \\
\hline Outlet plenum pressure $(\mathrm{MPa})$ & 15.17 \\
\hline
\end{tabular}

\section{SIMULATION RESULTS}

A RELAP-7 simulation was performed on the simplified TMI-1 reactor model described in the previous section, which includes 42 components such as pipes, core channels, flow branches, heat exchangers, pressurizer, etc. Steady state simulation results were obtained via accelerated time marching transient simulation. Simulation results were compared with data provided in [2], in terms of energy conservation. The core inlet/outlet coolant temperatures provided in [2] are $564.16 \mathrm{~K}$ and $591.15 \mathrm{~K}$, respectively, from which a $27 \mathrm{~K}$ core coolant temperature rise can be calculated. The RELAP-7 calculated core inlet/outlet temperatures are $564.06 \mathrm{~K}$ and $590.94 \mathrm{~K}$, respectively. The core coolant temperature rise is calculated to be $26.88 \mathrm{~K}$. The temperature differences between simulation results and data are in the order of $0.1 \mathrm{~K}$. The difference consists of two major error contributions from mesh descritization and power density descritization. Nevertheless, the RELAP-7 simulation results agree with provided data very well. For instance, the relative difference of the core coolant temperature rise between the simulation and the given data is only $0.44 \%$.

Figure 7 shows the calculated fluid temperature in the reactor model, including both primary and secondary loops. The simulation results clear show the primary side coolant temperature increae inside the core, as a result of extracting energy from fuels. Detailed fluid temperature profile in the three core channels is also shown in Figure 8 (from left to right, hot core channel, averge core channel and cold core channel). Different core channel coolant outlet temperatures can also be identified from the simulation as results of different fuel power densities in those channels. 


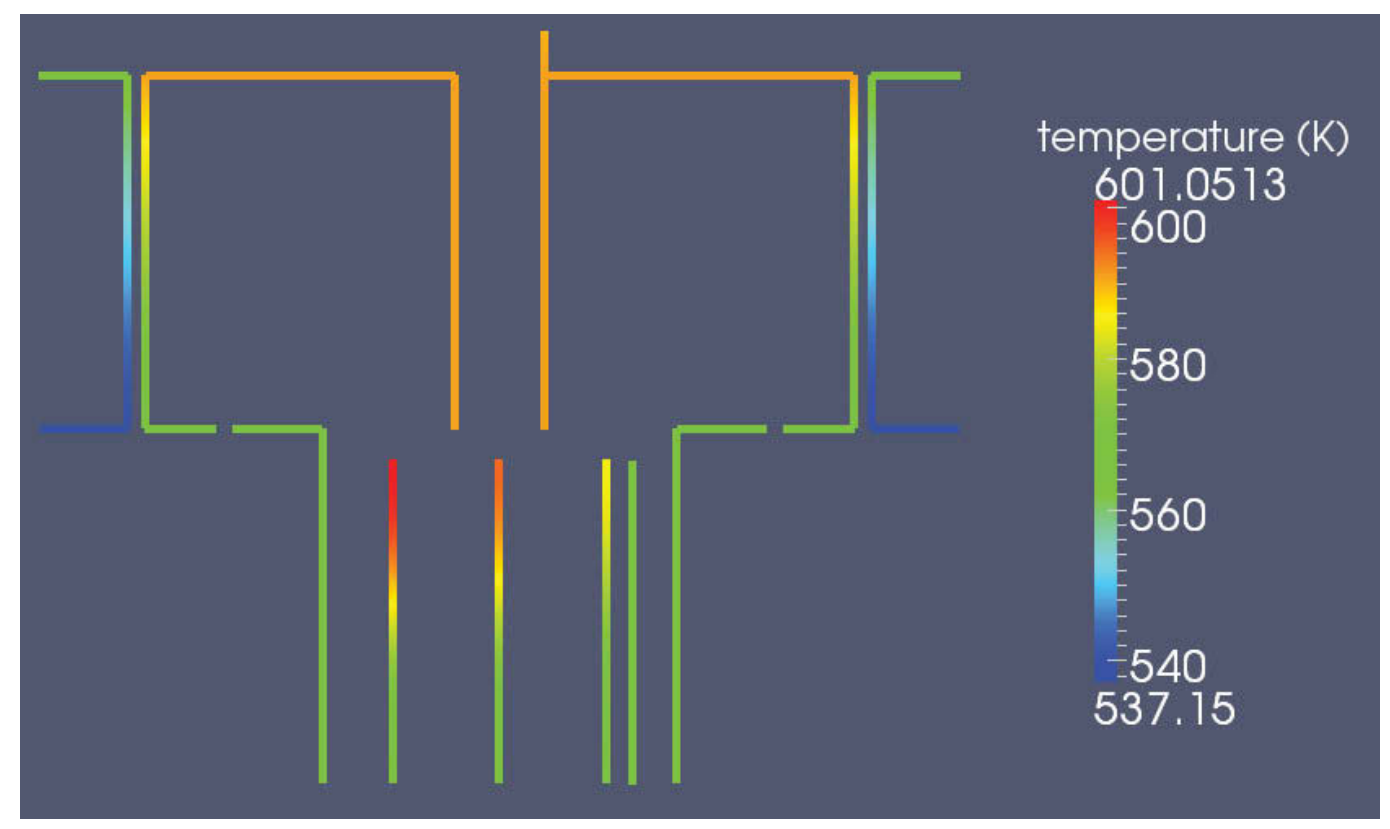

Figure 7. RELAP-7 calculated fluid temperature field

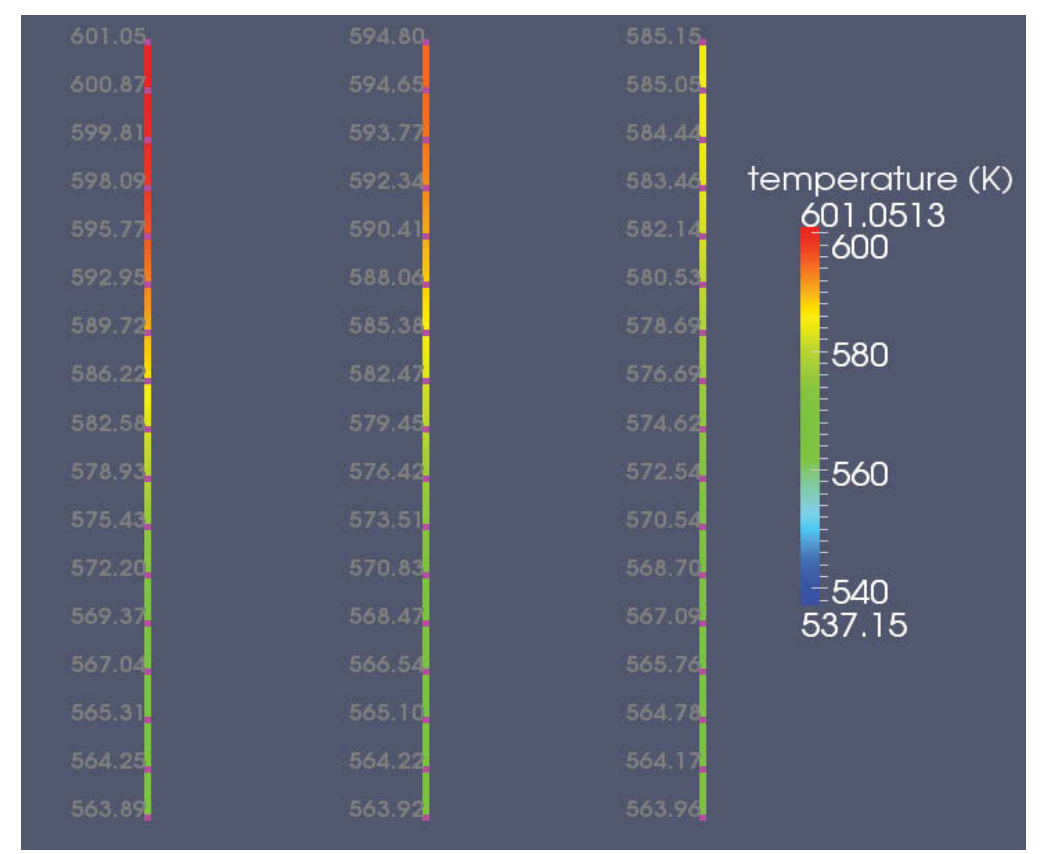

Figure 8. RELAP-7 calculated fluid temperature in three core channels

Figure 9 displays the hot core channel axial temperature profiles of coolant, clad surface and fuel center temperatures along the fuel height, resembling typical temperature profiles as given in [3]. As aslo shown in Figure 9, the coolant temperature increases continuously as a result of continuos heating from fuel. The fuel center temperature displays a sinusoidal-like shape reflecting the user input sinusoidal power density distribution. 


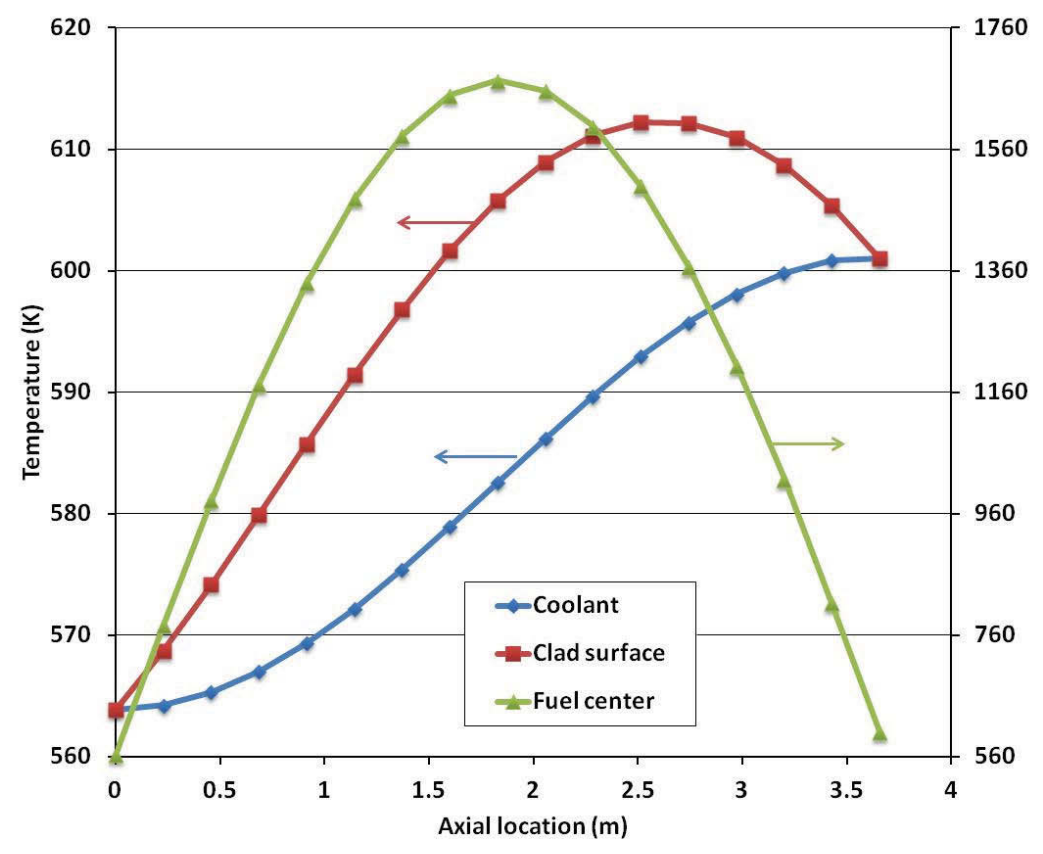

Figure 9. Axial temperature profiles along the fuel length

Radial fuel temperature profile is shown in Figure 10. The temperatures are taken from the very center fuel section from the hot channel, which represent the highest fuel temperature in the core. An analytical solution is also provided as fluid temperature, heat transfer coefficient and power density in the fuel pellet are given. The simulation results on fuel temperature agree with the analytical solution in general, except for a relatively larger discripency in the fuel center region. This is because a first order numerical scheme is used in the current version of RELAP-7 code to solve the heat conduction equation, and will be improved by using higher order numerical schemes in the future. 


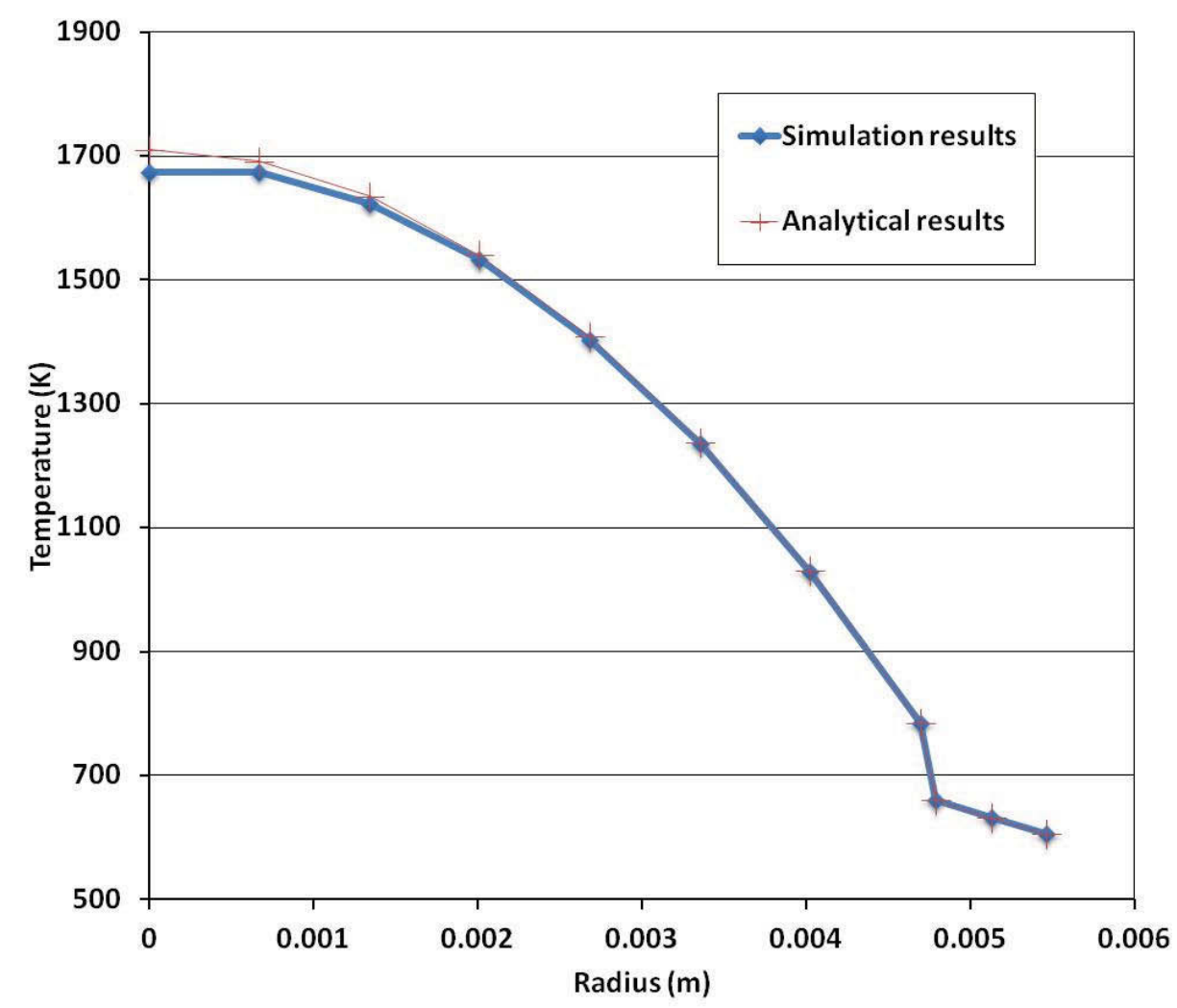

Figure 10. Radial fuel temperature profile

Figure 11 and Figure 12 show the RELAP-7 calculated pressure and velocity fields, respectively. The gravity is present in the simulation and pointing downward in Figure 11. The pressure profile shows a clear trend of higher pressure at lower positions. Sudden pressure decreases are also present across a flow branch as a result of local form (minor) loss, which is shown at position (1) in Figure 11 as an example. Pumps, on the contrary, server as momentum sources in the loop and therefore sudden pressure increases are expected across pumps, shown at position (2) in Figure 11 as an example. However, it has to be noted that the currently used TMI-1 NPP model is highly simplified, especially in terms of flow resistance across the core and heat exchangers. It is therefore not avaiable to compare the pressure field between RELAP-7 calculation and data provided in [2]. This, however, could be relatively easy to be implemented, as detailed input data and improved models are available. Figure 12 shows the velocity filed in the system from calculation results. Negative velocities are shown in secondary loops to distinguish from the primary loop, as a matter of fact that counter current heat exhangers are used in the simulation. Sudden velocity changes can also be observed in the system, which is a result of sudden pipe area changes. For instance, the increase of pipe area from cold leg pipe to the downcomer leads to a sudden decrease of coolant velocity. 


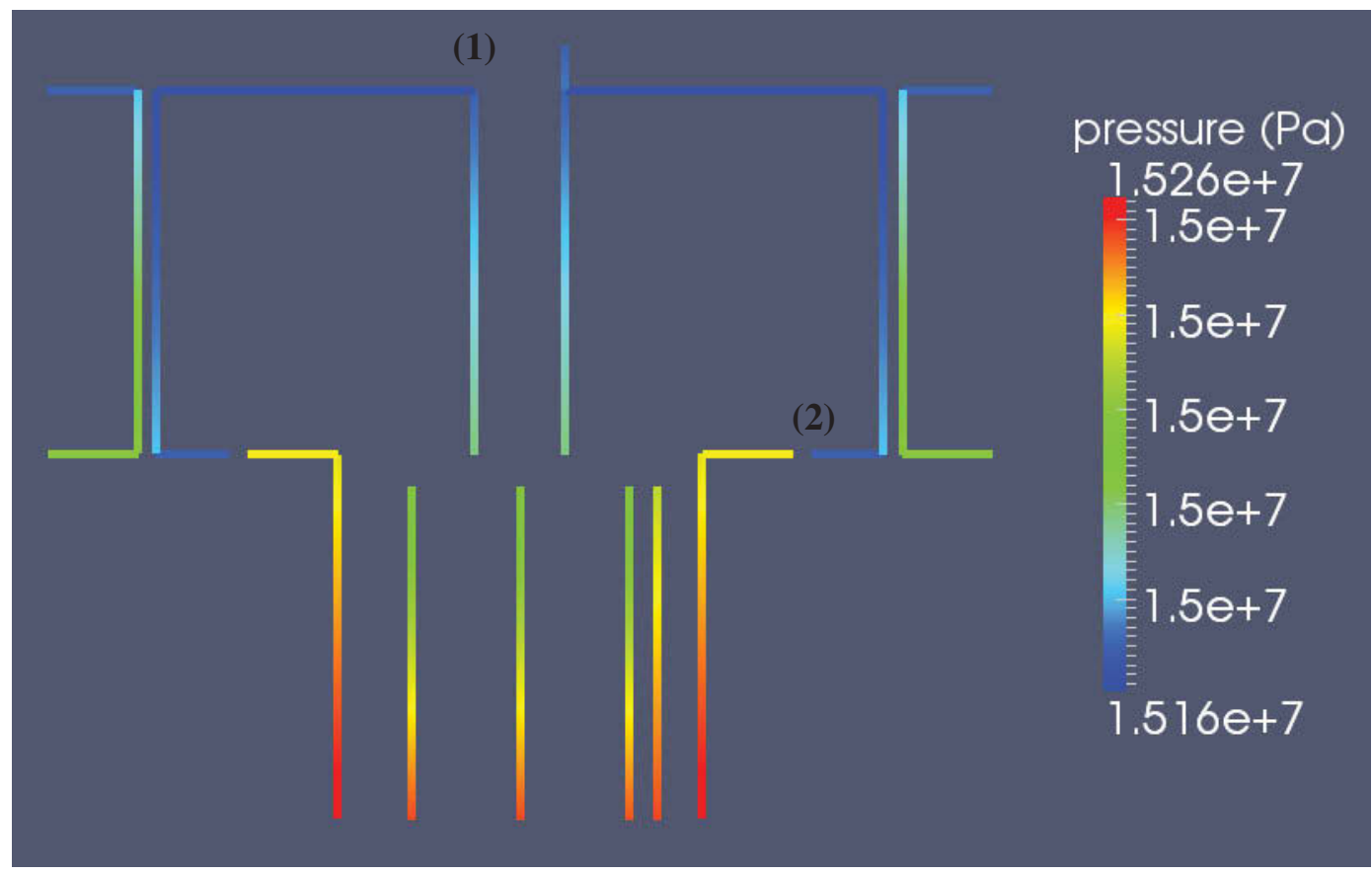

Figure 11. RELAP-7 calculated fluid pressure field

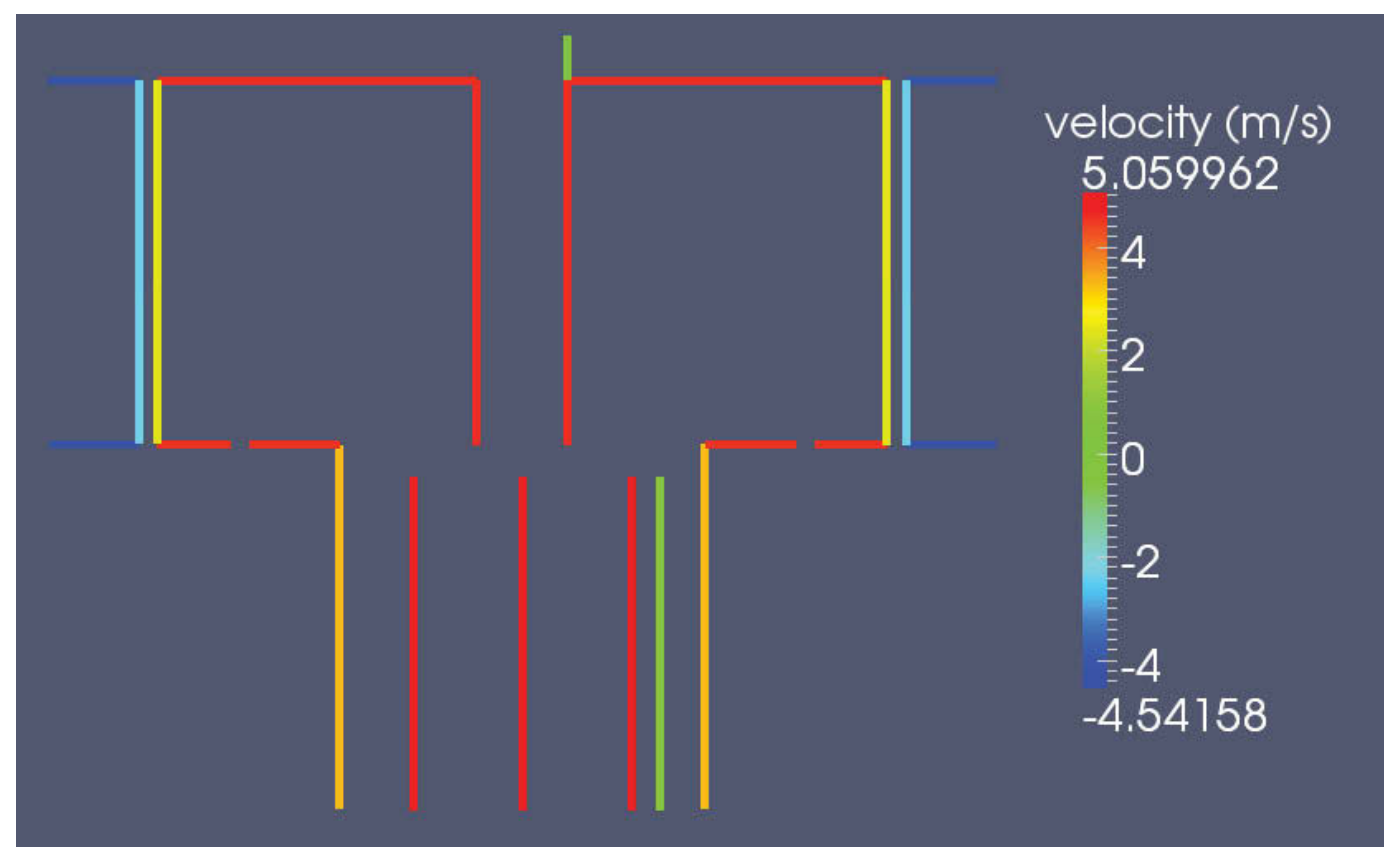

Figure 12. RELAP-7 calculated fluid velocity field

Figure 13 shows the coolant temperature in the heat exchanger. As explained previously, since two-phase flow capability has not been implemented in this current demonstration problem, the steam generator in this particular PWR was simplified as a counter current heat exchanger without phase change. Therefore, for this specific problem, the heat exchanger was redesigned to pass the same amount coolant mass flow rate in both primary and secondary sides. The primary side coolant temperature drop could be controlled to a desired value, i.e., core 
inlet/outlet coolant temperature difference. Figure 14 shows the loop-A heat exchanger primary and secondary side coolant temperature along the heat exchanger height. Two straight lines were obtained, which are the same as predicted from analytical solutions. This proves the complicated conjugated heat transfer was correctly computed in the heat exchanger component. However, as two-phase flow capability is available in future development, this simplified counter current single-phase heat exchanger could be replaced by a more realistic steam generator component.

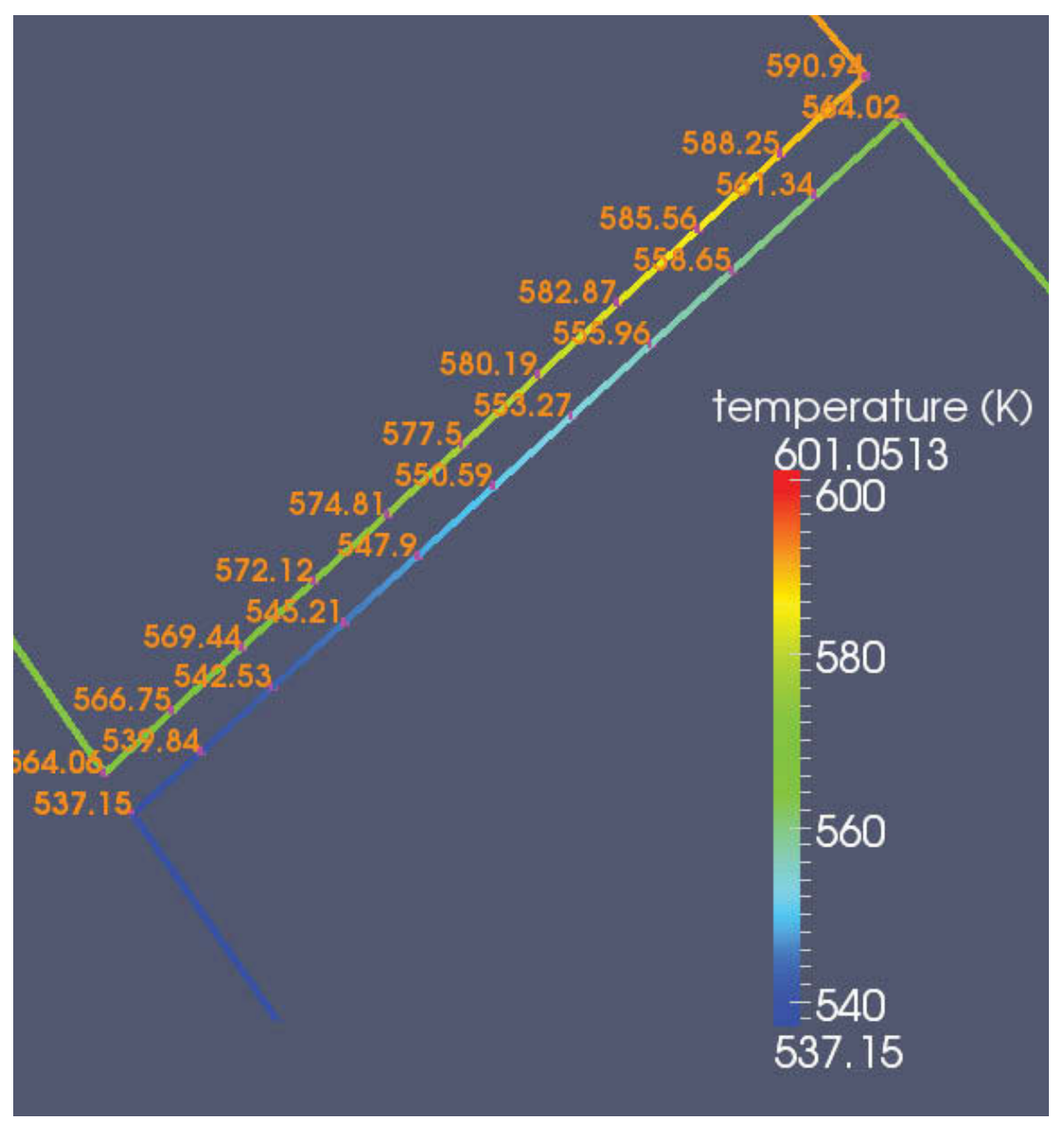

Figure 13. Fluid temperature in the loop-A heat exchanger 


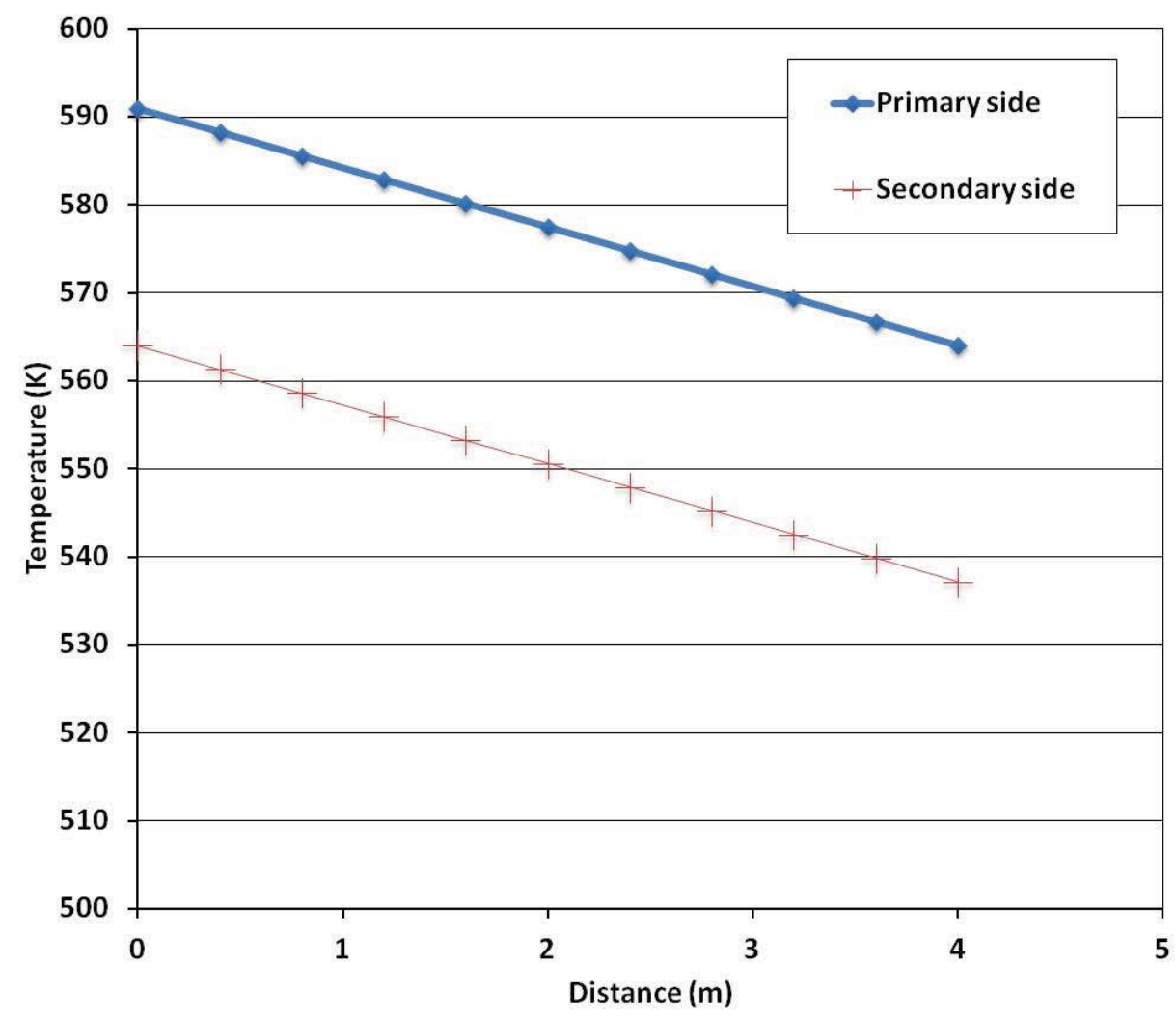

Figure 14. Fluid temperature in the loop-A heat exchanger along the heat exchanger height

\section{CONCLUSION AND FUTURE WORK}

The MOOSE based RELAP-7 code development effort is a relatively new and exciting effort, which only started at the beginning of FY12. However, the MOOSE framework enabled rapid development of the RELAP-7 code. With only a few months of development effort, a model PWR problem has been successfully simulated to steady state demonstrating the initial capabilities of the RELAP-7 code. The developmental efforts and results are very encouraging and demonstrate the RELAP-7 project is on a path to success.

The next stage of development is to demonstrate preliminary two-phase modeling capability through a simplified BWR station black out analysis, which will be reported in the next demonstration simulation report. Other work includes multi-dimensional neutronics coupling, more realistic components, reactor control and trip systems to be able to simulate transient conditions, etc.

\section{REFERENCES}

1. D. Gaston, et. Al., "MOOSE: A Parallel Computational Framework for Coupled Systems of Nonlinear Equation”, Nucl. Eng. Design, 239 (1768-1778), 2009. 
2. "Pressurized Water Reactor Main Steam Line Break (MSLB) Benchmark", Volume I: Final Specifications, NEA/NSC/DOC(99)8.

3. "Introduction to Nuclear Engineering", $3^{\text {rd }}$ Edition, J. R. Lamarsh and A. J. Baratta, 2001, page 433. 